\title{
Grinding control using artificial neural networks with AE feedback
}

\author{
Kexin Wang* \\ School of Mechanical Engineering, \\ Dalian University of Technology, \\ Dalian 116024, China \\ E-mail: wangkexin@dlut.edu.cn \\ *Corresponding author

\section{Xianjun Sheng} \\ Department of Electrical and Electronics Engineering, \\ Dalian University of Technology, \\ Dalian 116024, China \\ E-mail: sxianjun@dlut.edu.cn
}

\begin{abstract}
The surface roughness of workpiece in the process of ceramic grinding is affected by many factors. An online monitoring system for grinding roughness is proposed in this paper. This system monitors the AE signals that emerged in grinding to automatically identify wheel state and its parameters, wheel and workpiece speed, which inturn is used to control the workpiece roughness. We demonstrate the proposed system for internal grinding of ceramic work-piece with complex generatrix, and the results of experiments shows that the roughness is efficiently controlled.
\end{abstract}

Keywords: ceramic grinding; roughness; online monitoring system; acoustic emission; AE.

Reference to this paper should be made as follows: Wang, K. and Sheng, X. (2013) 'Grinding control using artificial neural networks with AE feedback', Int. J. Machine Intelligence and Sensory Signal Processing, Vol. 1, No. 1, pp.55-67.

Biographical notes: Kexin Wang is currently a Lecturer at the School of Mechanical Engineering, Dalian University of Technology, China. He received his PhD from Dalian University of Technology, China, in 2010. His research interests include $\mathrm{CNC}$ system and precision machining.

Xianjun Sheng is currently a Professor at the Department of Electrical and Electronics Engineering, Dalian University of Technology, China. She received her $\mathrm{PhD}$ degree from Dalian University of Technology, China, in 2003. Her research interests include $\mathrm{CNC}$ system and precision machining. 


\section{Introduction}

In recent years, because of engineering ceramics have high temperature, corrosion resistance, wear resistance, high strength, light quality and other features, which were widely used in many industry fields, such as: aerospace, defense, electronics, machinery, automobile, petroleum, chemicals, optical, etc. To obtain high dimensional accuracy and high surface quality, the main method of ceramic processing is grinding used diamond wheel. Relative dimensional accuracy, surface roughness is more difficult to control in ceramic grinding. The surface roughness of workpiece is affected by many factors (workpiece speed, wheel speed, depth of cut, wheel status, etc.), once the relevant grinding parameters changed, the roughness is difficult to guarantee. To solve this problem, the online monitoring system for grinding roughness is proposed in this paper, this system can control the roughness of ceramic workpiece in grinding by automatic adjusting grinding parameters in real time.

The object of grinding online monitoring technology is to ensure the optimal parameters in the whole process of grinding, and to make the results meet the intended requirements. Using this technology, the some physical quantities which generated in the grinding process, such as: force, power and acoustic emission (AE) can be monitored in real time. Then the grinding states can be reflected by these physical quantities. Furthermore, the grinding parameters can be adjusted in real time based on change of grinding states. Selecting monitored physical quantities is a key to establish the online monitoring system. This physical quantity should be easy to monitor, and can effectively reflect the grinding status. Compared to others, AE signals have some characteristics which are High sensitivity, immune to low frequencies interference ability and easy to install sensors. Therefore, AE signals have been widely used in grinding monitoring. Dornfeld and Cai (1984) used AE in grinding, his conclusion is that AE signal can be used to detect first contact with the wheel and workpiece. Inasaki, Blum and other scholars obtained similar conclusions in their study (Inasaki and Okamura, 1989; Wakuda and Inasaki, 1991; Blum And Dornfeld, 1993; Konig and Kumplen, 1993; Konig and Meyen, 1990). Byrne et al. (1995) presented several characteristics of signal which was extracted from the AE signal to monitor and analysis for grinding. In addition, AE had also been successfully applied to monitor the collision, roughness and wheel condition in grinding (Meyen, 1991; Kwak and Song, 2001).

This paper presents a surface roughness on-line monitoring system for ceramic grinding, the core of system are two artificial neural networks (ANN) and the feedback of system are AE signals. The AE signal is feedback to the core of the two ANN systems. In grinding, the AE signals were picked up to identify wheel state, and the wheel speed, workpiece speed and other parameters could be automatic adjusted based on wheel state. Then the workpiece roughness could be effectively controlled. In Section 2, the grinding surface roughness model of ceramic workpiece which is rotating body with complex generatrix was established. The roughness online monitoring system was established in Section 3. In Section 4, two ANN were trained by means of experiments. The application test of the online monitoring system was described in Section 5, and conclusion in Section 6. 


\section{Surface roughness model}

The workpiece is fused silica ceramic rotating body with complex generatrix (shown in Figure 1). The material property parameters are as follows: bending strength (50 Mpa); density $\left(2.07 \mathrm{~g} / \mathrm{cm}^{3}\right)$; the average roughness of inner surface without grinding is $6.1 \mu \mathrm{m}$. The requirements of processing are that the workpiece would be removed specified wall thickness at the designated area on the inner surface using internal grinding. After grinding, the processing region should have uniform roughness and inner surface $R a$ should be less than $1.2 \mu \mathrm{m}$. To prevent moisture, the workpiece must be ground without grinding fluid. The resin-bonded diamond wheel is used to grinding, which diameter is $70 \mathrm{~mm}$. The inner surface of workpiece should be measured first and then be ground as the workpiece generatrix was unknown. For this reason, a machine with measurement-processing integrated structure was designed, the further information of the machine was described in literature (Wang et al., 2010).

Figure 1 The fused silica ceramic workpiece

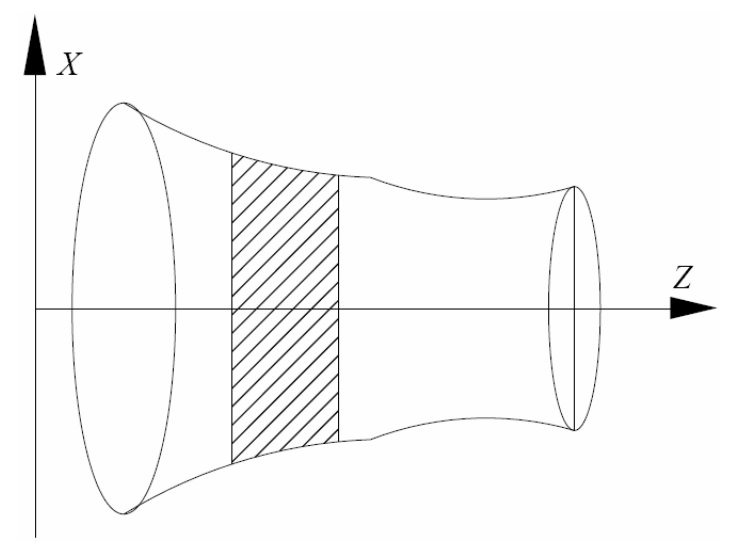

According to grinding surface roughness, many scholars had done a lot of research, and a series of roughness model had been presented. In cylindrical and internal grinding field, a representative model was proposed by Malkin (1989):

$$
R_{a}=\left(\frac{R_{0}}{\sqrt{m}}\right)\left(\frac{v_{w} L}{v_{s} \sqrt{d_{e}}} \cdot \frac{s_{t}}{b_{s}}\right)^{0.8}+R_{\infty}
$$

where $R_{0}$ and $R_{\infty}$ were empirical constants, $m$ was the ratio of $R_{t}$ and $R_{a}, v_{w}, v_{s}$ were linear velocity of workpiece and wheel respectively, $L$ was the distance between the effective edged of wheel, $b_{s}$ is effective width of the wheel, $S_{t}$ is crossfeed. Since the spherical wheel was used, $d_{e}$ was wheel equivalent diameter.

However, grinding is a very complex process, the removal mechanism is not yet very clear. Many factors affect the grinding result, and most of its influence on the roughness is non-linear. Therefore, the roughness model which was indicated by equation (1) was different from the actual grinding, the empirical model derived from experimental was more common (Snoeys et al., 1974; Kedrov, 1980; Banerjee and Hillier, 1972): 


$$
R_{a} \propto R_{1}\left(\frac{v_{w} a}{v_{s}}\right)^{x} \cdot\left(\frac{s_{t}}{b_{s}}\right)^{z}
$$

where $R_{1}, x, z$ were constants determined by experiment $(0.15<x<0.6,0.5<z<1)$, a was cutting depth, the rest were same as equation (1). Equation (2) shown that workpiece speed, wheel speed, depth of cut, crossfeed and wheel effective width were main factors influencing the roughness.

In this paper, the roughness model of ceramic workpiece is similar to equation (2). But there are two main differences: first, the effective width is related to depth of cut because using arc wheel; second, the grinding process cannot use the grinding fluid, the wheel wear process is quickly, so the wheel factor must be considered. According the differences, equation (2) can be modified in two ways. The relationship between effective width and depth of cut is shown in Figure 4, and expressed as:

$$
b_{s}=2 \sqrt{2 r \cdot a}
$$

where $r$ was radius of wheel cambered surface. On the other hand, the parameter ' $k$ ' can be defined to represent sharpness of wheel. Then the roughness model can be expressed as:

$$
R_{a} \propto R_{1}\left(\frac{v_{w}}{v_{s}}\right)^{x} \cdot\left(\frac{s_{t}}{2 \sqrt{2 R}}\right)^{z} \cdot a^{x-\frac{1}{2} z} \cdot k^{y}
$$

Figure 2 The effective width and cutting depth of grinding wheel
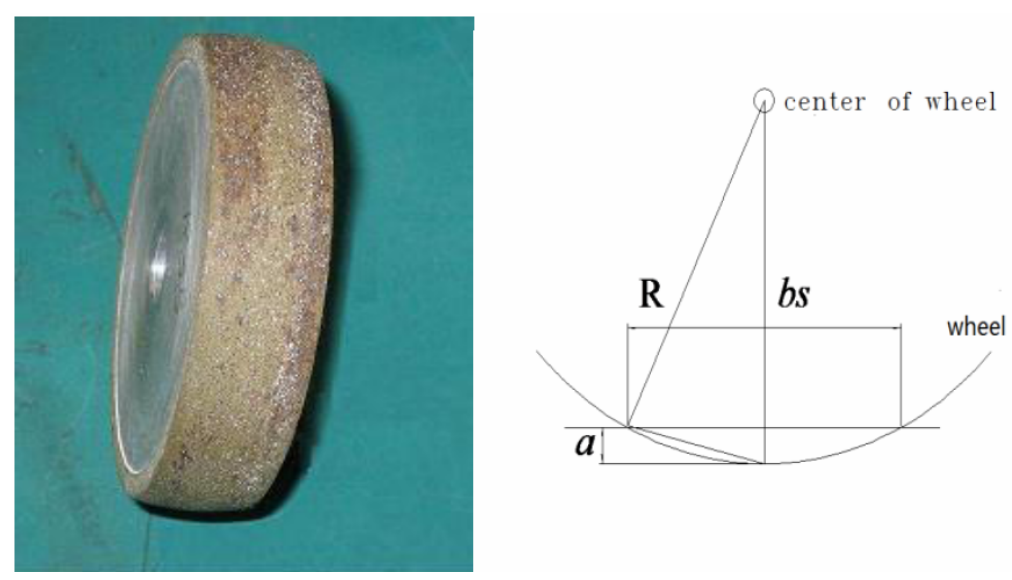

\section{Surface roughness online monitor system}

According to the model expressed by equation (4), the surface roughness of workpiece is affected by workpiece speed, wheel speed, depth of cut, crossfeed and wheel status, once these grinding parameters changed, the roughness is changed. Under the ideal condition, the roughness could be effectively controlled by optimising grinding parameters based on experiences. However, the wheel would be wear, and the workpiece speed was changing 
constantly because of complex generatrix of workpieces, these changes led to the roughness unstable in actual grinding process. Therefore, to control the roughness, these changes should be detect in time, and some grinding parameters be reset online. In this paper, a grinding roughness online monitoring system is proposed, this system can monitor the AE signal to identify wheel state, then wheel and workpiece speed and other parameters can be automatic adjusted based on wheel state, the workpiece roughness could be effectively controlled. The key problem of the system is to establish the mapping relationship between these physical quantities, such as: the relationship between the wheel state and AE signals, grinding parameters and the roughness. These mappings can be obtained through system identification. The ANN was widely used in grinding because of approximation of non-linear mapping capability, handling multiple variables, automatically learning and training.

The grinding roughness online monitoring system is shown in Figure 3, which includes grinding parameters pre-set module, ANN module for identification the wheel state (ANN1), ANN module for grinding parameters optimisation (ANN2), AE signals feedback module and conversion module for line speed to rotational speed of wheel and workpiece. The operation principle of system can be described as follows:

1 the parameters (including the roughness, depth of cut, crossfeed, wheel sharpness) were input to ANN2, and the optimised workpiece speed and wheel speed were used as the outputs of ANN2, and grinding could be started with optimised speed parameter.

2 in grinding process, the AE signals were acquired as feedback, and the signals were input to ANN1 together with grinding depth, wheel speed and workpiece speed to identify wheel sharpness

3 based on new wheel sharpness, the ANN2 was used to generate new speed parameters, then wheel speed and workpiece speed could be real-time adjusted, and the roughness could be guarantee.

Figure 3 The grinding roughness on-line monitoring system (see online version for colours)

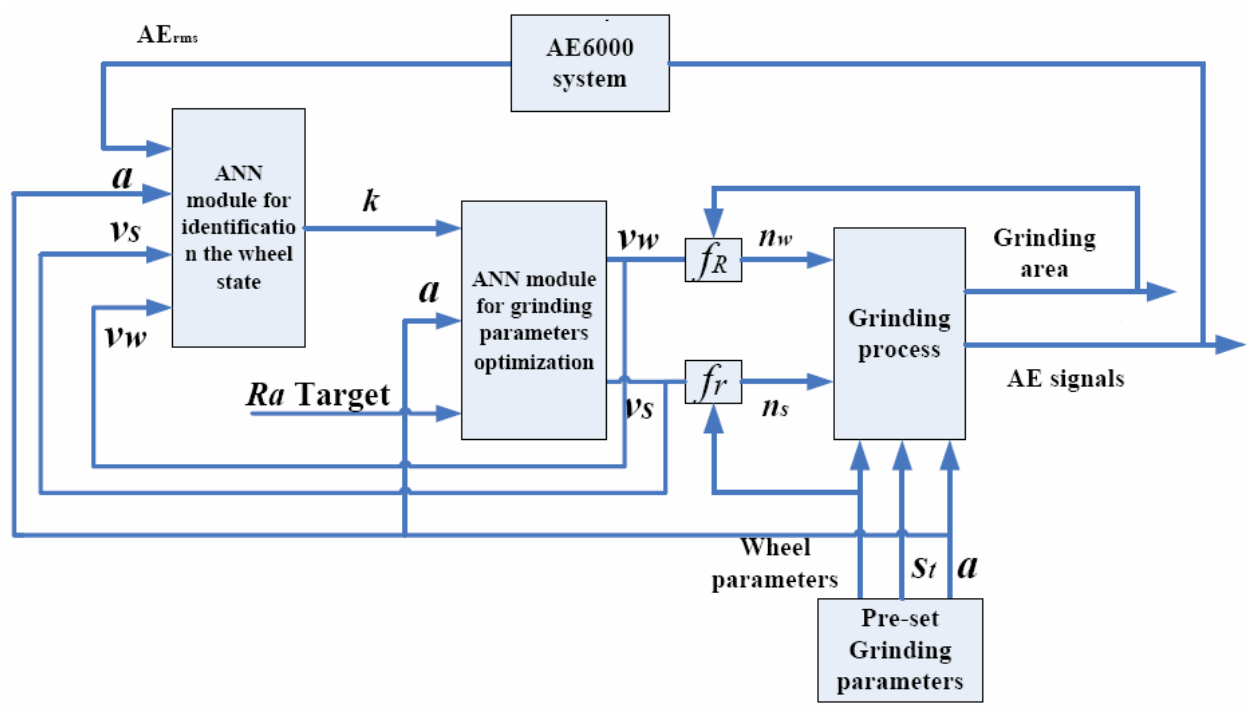


Specially, in this system, AE signals were not sent in ANN2 to optimised, but were sent in ANN1 to identify wheel sharpness with other parameters. The reason for this is that the AE signals were affected by $v_{w}, v_{s}$ and $a$, these parameters would lead to AE signals changes even if the $\mathrm{k}$ unchanged. In order to make the AE signals can accurately reflect the grinding wheel sharpness, the system used ANN1 to eliminate this effect, like 'decoupling', namely, and the $k$ was reflected by AE signals and other parameters. In addition, because the workpiece section radius would change with the grinding position, in order to ensure that the same ratio of $v_{w}$ and $v_{s}$, the system also adjust $v_{w}$ or $v_{s}$ according to the grinding position. For grinding roughness On-line monitoring system, the key is to build ANN and train these ANN through the experimental data.

The sensor of AE is located in the hole of spindle (shown in Figure 4), the micro sensor is located in front of the hole closed to the wheel, the special device used to transduction signal to the transmitter at the back of the hole, the receiver is fixed to the spindle end cover, is not contact with the transmitter, and the distance between the two is less than $1 \mathrm{~mm}$. This installation method to ensure the tool/work/sensor distance fixed when grinding.

Figure 4 Through-hole spindle design and installation method of AE sensor

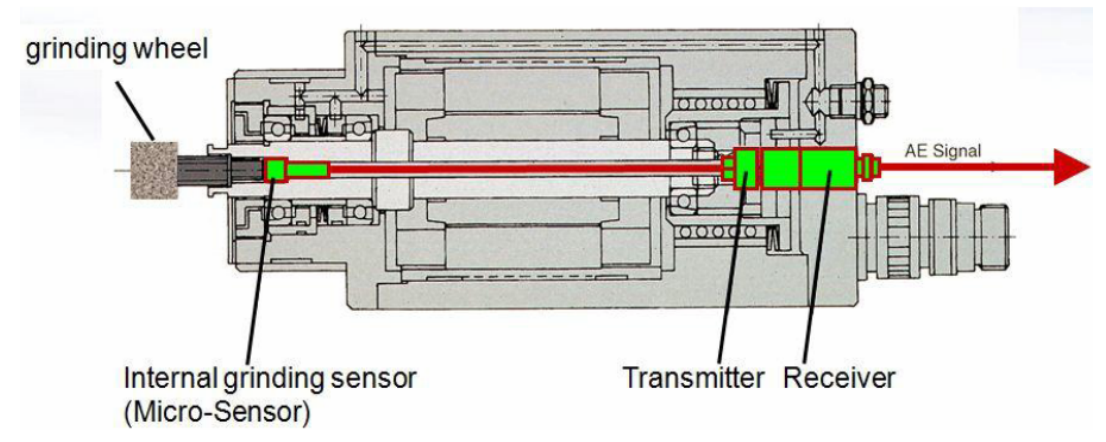

\section{Training ANN}

In order to train two ANN, grinding experiments must be carried out to obtain the data for learning. The grinding experiments were performed on a special NC grinding machining (Wang et al., 2010). The conditions of experiments were as follows:

1 a fused quartz ceramic workpiece, $150 \times \Phi 160$ [the cylindrical workpiece was designed to easily measure roughness, the workpiece and clamping method were shown in Figure 5(a)]

2 a resin-bonded spherical diamond wheel of 100 concentration, 50 grit size, $d_{s}=69.626 \mathrm{~mm}$ and thickness $D=16 \mathrm{~mm}$

3 dry grinding

4 all experiments were performed down-grinding. 
Table 1 Experimental parameters level

\begin{tabular}{lcccc}
\hline Parameters level & $V_{s}(\mathrm{~m} / \mathrm{s})$ & $V_{w}(\mathrm{~mm} / \mathrm{s})$ & $A(\mu \mathrm{m})$ & $k$ \\
\hline 1 & $11(3,000 \mathrm{rpm})$ & $23.55(3 \mathrm{rpm})$ & 20 & 1 \\
2 & $22(6,000 \mathrm{rpm})$ & $47.1(6 \mathrm{rpm})$ & 50 & 0.75 \\
3 & $33(9,000 \mathrm{rpm})$ & $70.65(9 \mathrm{rpm})$ & 100 & 0.5 \\
4 & $44(12,000 \mathrm{rpm})$ & $94.2(12 \mathrm{rpm})$ & 150 & 0.25 \\
\hline
\end{tabular}

Table 2 Grinding experimental parameters

\begin{tabular}{|c|c|c|c|c|c|c|c|c|c|}
\hline No. & $\begin{array}{c}V_{s} \\
(\mathrm{~m} / \mathrm{s})\end{array}$ & $\begin{array}{c}V_{w} \\
(\mathrm{~mm} / \mathrm{s})\end{array}$ & $\begin{array}{c}a \\
(\mu m)\end{array}$ & $k$ & No. & $\begin{array}{c}V_{s} \\
(\mathrm{~m} / \mathrm{s})\end{array}$ & $\begin{array}{c}V_{w} \\
(\mathrm{~mm} / \mathrm{s})\end{array}$ & $\begin{array}{c}a \\
(\mu m)\end{array}$ & $k$ \\
\hline 1 & 11 & 23.55 & 20 & 1 & 33 & 11 & 23.55 & 20 & 1 \\
\hline 2 & 22 & 23.55 & 20 & 1 & 34 & 11 & 23.55 & 50 & 1 \\
\hline 3 & 33 & 23.55 & 20 & 1 & 35 & 11 & 23.55 & 100 & 1 \\
\hline 4 & 44 & 23.55 & 20 & 1 & 36 & 11 & 23.55 & 150 & 1 \\
\hline 5 & 11 & 47.1 & 50 & 0.75 & 37 & 22 & 47.1 & 20 & 0.75 \\
\hline 6 & 22 & 47.1 & 50 & 0.75 & 38 & 22 & 47.1 & 50 & 0.75 \\
\hline 7 & 33 & 47.1 & 50 & 0.75 & 39 & 22 & 47.1 & 100 & 0.75 \\
\hline 8 & 44 & 47.1 & 50 & 0.75 & 40 & 22 & 47.1 & 150 & 0.75 \\
\hline 9 & 11 & 70.65 & 100 & 0.5 & 41 & 33 & 70.65 & 20 & 0.5 \\
\hline 10 & 22 & 70.65 & 100 & 0.5 & 42 & 33 & 70.65 & 50 & 0.5 \\
\hline 11 & 33 & 70.65 & 100 & 0.5 & 43 & 33 & 70.65 & 100 & 0.5 \\
\hline 12 & 44 & 70.65 & 100 & 0.5 & 44 & 33 & 70.65 & 150 & 0.5 \\
\hline 13 & 11 & 94.2 & 150 & 0.25 & 45 & 44 & 94.2 & 20 & 0.25 \\
\hline 14 & 22 & 94.2 & 150 & 0.25 & 46 & 44 & 94.2 & 50 & 0.25 \\
\hline 15 & 33 & 94.2 & 150 & 0.25 & 47 & 44 & 94.2 & 100 & 0.25 \\
\hline 16 & 44 & 94.2 & 150 & 0.25 & 48 & 44 & 94.2 & 150 & 0.25 \\
\hline 17 & 11 & 23.5 & 20 & 1 & 49 & 11 & 23.55 & 20 & 1 \\
\hline 18 & 11 & 47.1 & 20 & 1 & 50 & 11 & 23.55 & 20 & 0.75 \\
\hline 19 & 11 & 70.65 & 20 & 1 & 51 & 11 & 23.55 & 20 & 0.5 \\
\hline 20 & 11 & 94.2 & 20 & 1 & 52 & 11 & 23.55 & 20 & 0.25 \\
\hline 21 & 22 & 23.5 & 50 & 0.755 & 53 & 22 & 47.1 & 50 & 1 \\
\hline 22 & 22 & 47.1 & 50 & 0.755 & 54 & 22 & 47.1 & 50 & 0.75 \\
\hline 23 & 22 & 70.65 & 50 & 0.755 & 55 & 22 & 47.1 & 50 & 0.5 \\
\hline 24 & 22 & 94.2 & 50 & 0.755 & 56 & 22 & 47.1 & 50 & 0.25 \\
\hline 25 & 33 & 23.5 & 100 & 0.5 & 57 & 33 & 70.65 & 100 & 1 \\
\hline 26 & 33 & 47.1 & 100 & 0.5 & 58 & 33 & 70.65 & 100 & 0.75 \\
\hline 27 & 33 & 70.65 & 100 & 0.5 & 59 & 33 & 70.65 & 100 & 0.5 \\
\hline 28 & 33 & 94.2 & 100 & 0.5 & 60 & 33 & 70.65 & 100 & 0.25 \\
\hline 29 & 44 & 23.5 & 150 & 0.25 & 61 & 44 & 94.2 & 150 & 0.25 \\
\hline 30 & 44 & 47.1 & 150 & 0.25 & 62 & 44 & 94.2 & 150 & 0.25 \\
\hline 31 & 44 & 70.65 & 150 & 0.25 & 63 & 44 & 94.2 & 150 & 0.25 \\
\hline 32 & 44 & 94.2 & 150 & 0.25 & 64 & 44 & 94.2 & 150 & 0.25 \\
\hline
\end{tabular}


The purpose of experiments was to find the relationship between grinding parameters $\left(a, k, v_{w}, v_{s}\right)$ and the roughness or AE signals. The level of grinding parameters used in experiments were list in Table 1 . The wheel sharpness $(k)$ was defined as follows: the ' $k$ ' was defined as 1 if it was dressing just; after using, the ' $k$ ' would be defined as $0.75,0.5$, 0.25 , representing light wear, moderate wear, and severe wear, respectively. The total of 64 sets experiments which listed in Table 2 were designed based on different parameters. $\mathrm{AE}_{\mathrm{rms}}$ (root mean square of $\mathrm{AE}$ signals)were record in grinding, and the roughness was measured with surfcorder SE-3H profilometer after each grinding [shown in Figure 5(b)].

Figure 5 The ceramic workpiece clamping and roughness measuring method

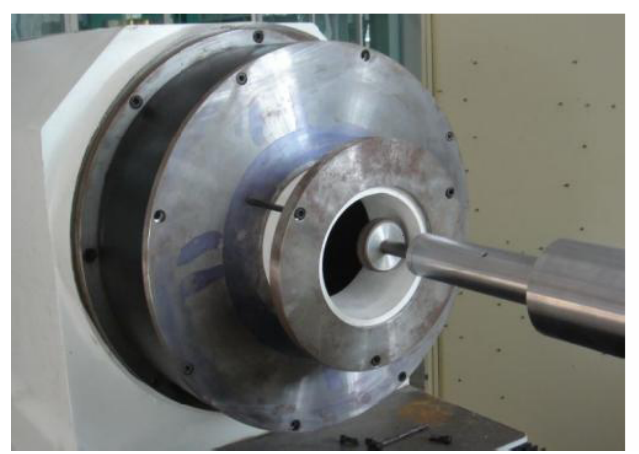

(a)

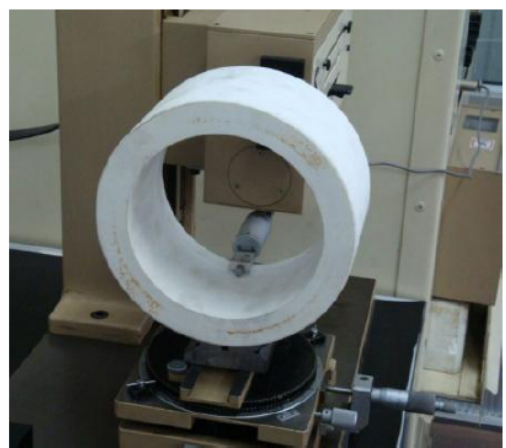

(b)

The total of 64 sets experiments data were divided into four groups. The $v_{s}$ was varied in the first 16 sets experiments, the $v_{w}$ in the second group, the $a$ was varied in the third and the $k$ in the fourth. Therefore the four groups results data will respectively illustrate the effect of processing parameters on surface roughness and $\mathrm{AE}_{\mathrm{rms}}$. The first group results data were analysed in order to find the relationship between $v s$ and $R a$ and $\mathrm{AE}_{\mathrm{rms}}$, the second for the relationship between $v_{w}$ and $R a$ and $\mathrm{AE}_{\mathrm{rms}}$, the third for the relationship between $a$ and $R a$ and $\mathrm{AE}_{\mathrm{rms}}$, the fourth for the relationship between $k$ and $R a$ and $\mathrm{AE}_{\mathrm{rms}}$. The experiments results were presented in Figure 6 (note: the value of $A_{\mathrm{rms}}$ was dimensionless number between $0-1$ after normalisation processing). The results indicated that $R a$ increased along with the rising of $v_{w}, a$, and $k$, and decreased with the rising of $v_{s}$; When $v_{w}$, and $a$ raised, $\mathrm{AE}_{\mathrm{rms}}$ increased, and $\mathrm{AE}_{\mathrm{rms}}$ decreased with increasing $v_{s}$ and $k$. The figure also shown that $v_{s}$ and $a$ parameter had great effect on the roughness, and $a$ had obvious impact on $\mathrm{AE}_{\mathrm{rms}}$.

In the system shown in Figure 3, ANN1 and ANN2 were the system kernel. The BP structure was used to construct ANN (Figure 7). After normalised, the 42 sets of experimental data were input to train two ANN. The rest 10 sets of data were input in the trained ANN as test data to test network performance after training completed, and the results were shown in Tables 3 and 4. The average recognition accuracy of ANN1 was $A_{1}=1-\frac{1}{N} \sum_{i=1}^{10}\left|\frac{t_{i}-a_{i}}{t_{i}}\right|=1-0.0397=96.03 \%$, and because ANN2 had two outputs $\left(v_{s}, v_{w}\right)$, the average recognition accuracy of ANN2 could be expressed as:

$$
A_{2}=A_{2 v_{s}} \cdot A_{2 v_{w}}=96.53 \% \times 89.58 \%=86.47 \% \text {. }
$$


Figure 6 The influence of grinding to roughness and AE signals, (a) the influence of $v_{s}$ to roughness and $\mathrm{AE}$ signals $(\mathrm{b})$ the influence of $v_{w}$ to roughness and $\mathrm{AE}$ signals (c) the influence of a to roughness and AE signals (d) the influence of $k$ to roughness and $\mathrm{AE}$ signals
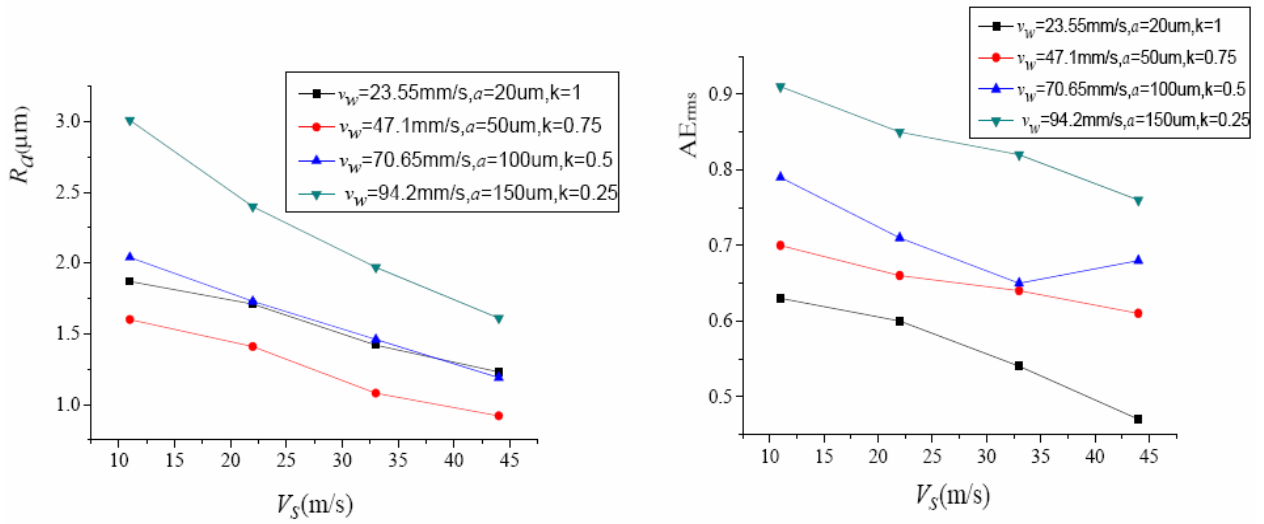

(a)
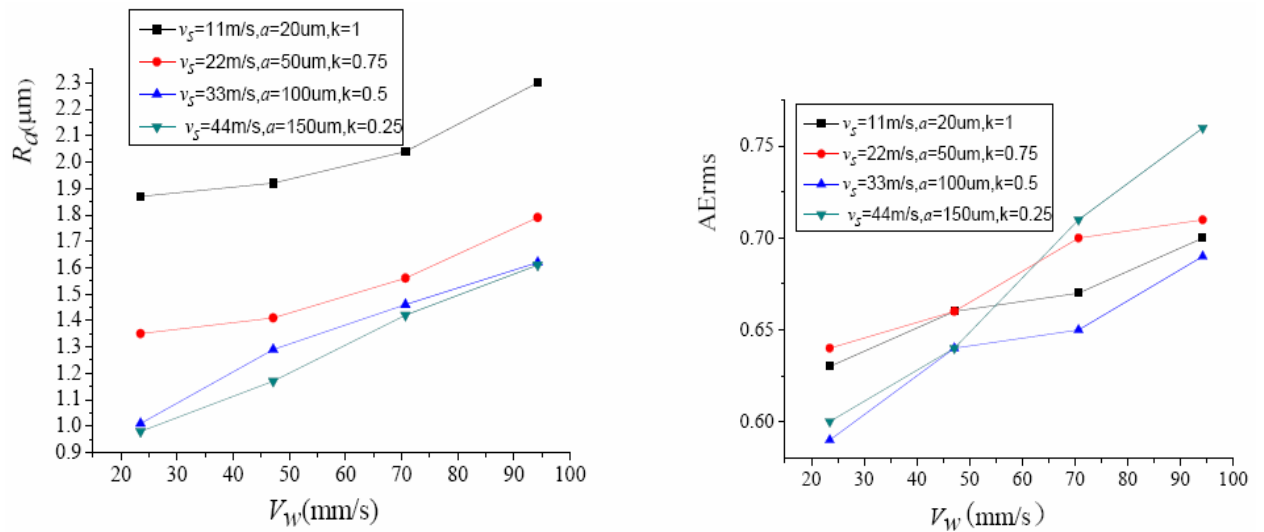

(b)
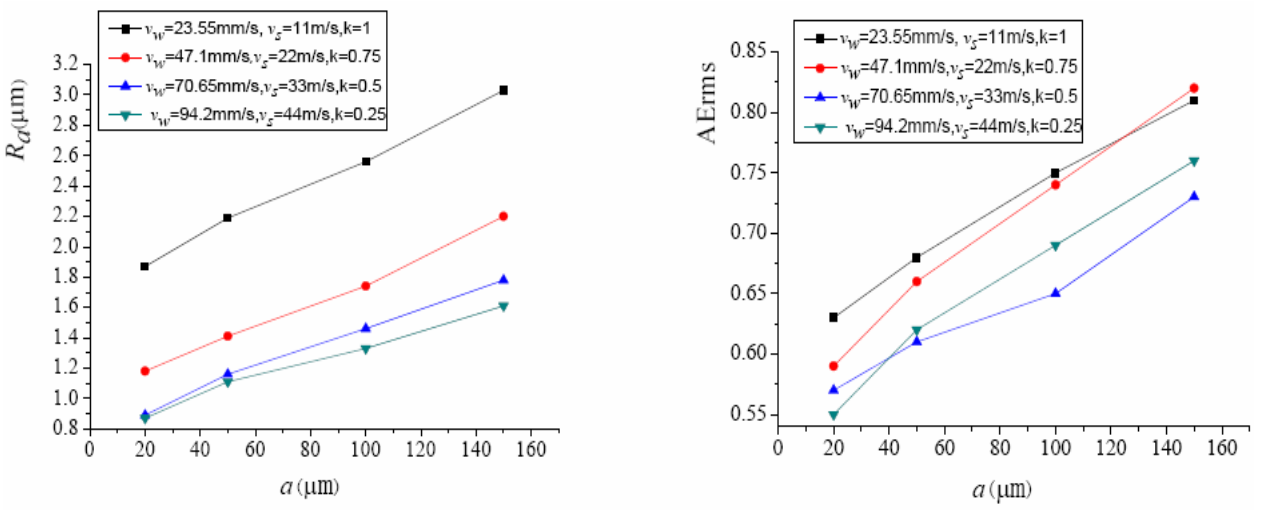

(c) 
Figure 6 The influence of grinding to roughness and AE signals, (a) the influence of $v_{s}$ to roughness and $\mathrm{AE}$ signals $(\mathrm{b})$ the influence of $v_{w}$ to roughness and $\mathrm{AE}$ signals

(c) the influence of a to roughness and AE signals (d) the influence of $\mathrm{k}$ to roughness and $\mathrm{AE}$ signals (continued)
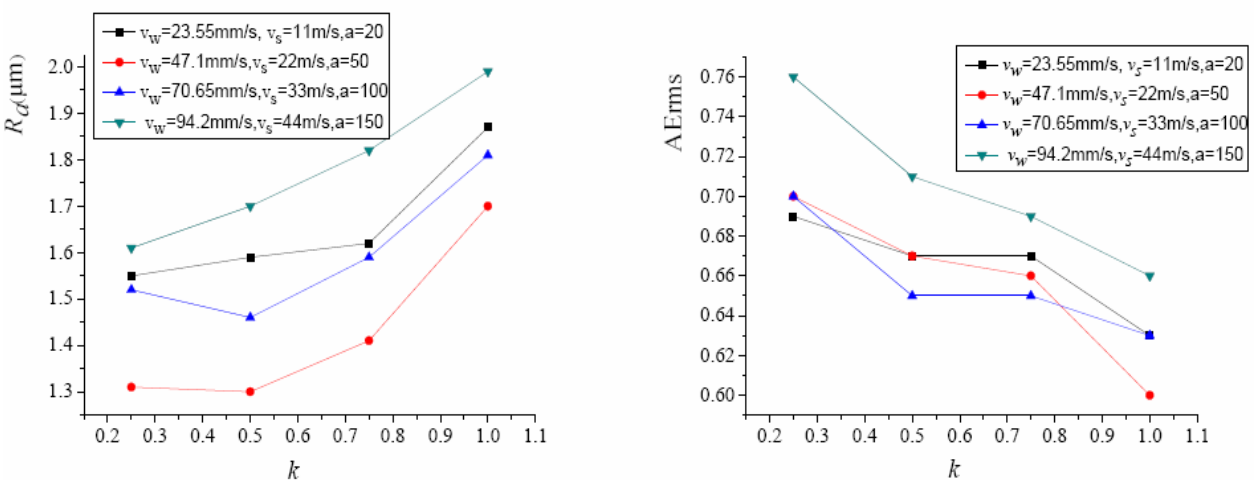

(d)

Figure 7 Wheel status identification ANN and grinding parameter optimisation ANN, (a) wheel status identification ANN (b) grinding parameter optimisation ANN

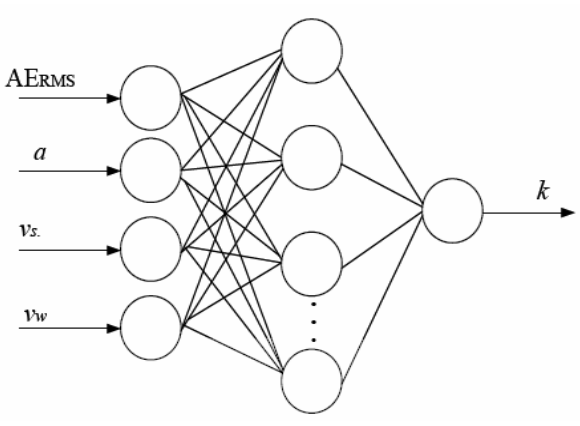

(a)

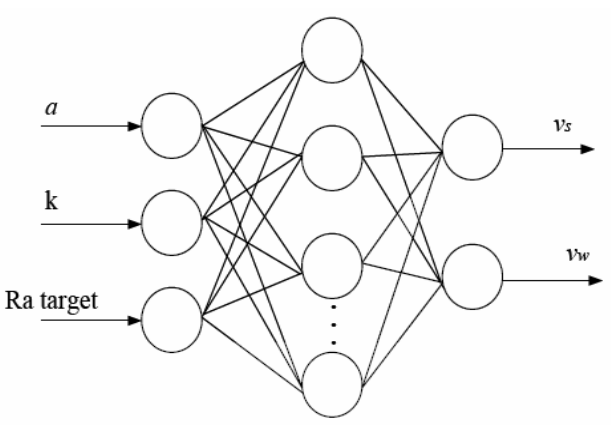

(b)

Table 3 The identification results of wheel status ANN

\begin{tabular}{lccc}
\hline Desired output $(k)$ & Actual output & Absolute error & Relative error (\%) \\
\hline 1 & 1 & 0 & 0 \\
1 & 1 & 0 & 0 \\
0.75 & 0.78265 & -0.03265 & -4.35333 \\
0.75 & 0.75977 & -0.00977 & -1.30333 \\
0.75 & 0.736 & 0.019 & 2.51656 \\
1 & 0.94398 & 0.05602 & 5.6025 \\
0.75 & 0.69273 & 0.05727 & 7.63667 \\
0.75 & 0.7798 & -0.0298 & -3.97333 \\
0.75 & 0.79338 & -0.04338 & -5.78333 \\
0.5 & 0.45722 & 0.04278 & 8.555 \\
\hline
\end{tabular}


Table 4 The identification results of grinding parameter optimisation ANN

\begin{tabular}{|c|c|c|c|c|c|c|c|}
\hline \multicolumn{2}{|c|}{ Desired output } & \multicolumn{2}{|c|}{ Actual output } & \multicolumn{2}{|c|}{ Absolute error } & \multicolumn{2}{|c|}{ Relative error (\%) } \\
\hline $\begin{array}{l}V_{s} \\
(\mathrm{~m} / \mathrm{s})\end{array}$ & $\begin{array}{c}V_{w} \\
(\mathrm{~mm} / \mathrm{s})\end{array}$ & $\begin{array}{c}V_{s} \\
(\mathrm{~m} / \mathrm{s})\end{array}$ & $\begin{array}{c}V_{w} \\
(\mathrm{~mm} / \mathrm{s})\end{array}$ & $V_{s}$ & $V_{w}$ & $V_{s}$ & $V_{w}$ \\
\hline 22 & 70.65 & 19.7186 & 71.63385 & 2.2814 & -0.98385 & 10.37 & -1.39256 \\
\hline 22 & 94.2 & 23.7809 & 94.15 & -1.7809 & 0.05 & -8.095 & 0.05308 \\
\hline 33 & 23.5 & 31.6481 & 25.95862 & 1.3519 & -2.45862 & 4.09667 & -10.46221 \\
\hline 33 & 47.1 & 33.1859 & 46.29876 & -0.1859 & 0.80125 & -0.56333 & 1.70116 \\
\hline 33 & 94.2 & 35.0537 & 93.21742 & -2.0537 & 0.98258 & -6.22333 & 1.04308 \\
\hline 44 & 23.5 & 44 & 31.46225 & 0 & -7.96225 & 0 & -33.88194 \\
\hline 44 & 47.1 & 44 & 53.02464 & 0 & -5.92464 & 0 & -12.57884 \\
\hline 44 & 70.65 & 44 & 80.1825 & 0 & -9.53249 & 0 & -13.49256 \\
\hline 11 & 23.55 & 11 & 28.84114 & 0 & -5.29114 & 0 & -22.46769 \\
\hline 11 & 23.55 & 11.594 & 25.22386 & -0.594 & -1.67386 & -5.4 & -7.10769 \\
\hline
\end{tabular}

Figure 8 The roughness comparison with and without grinding online monitoring system

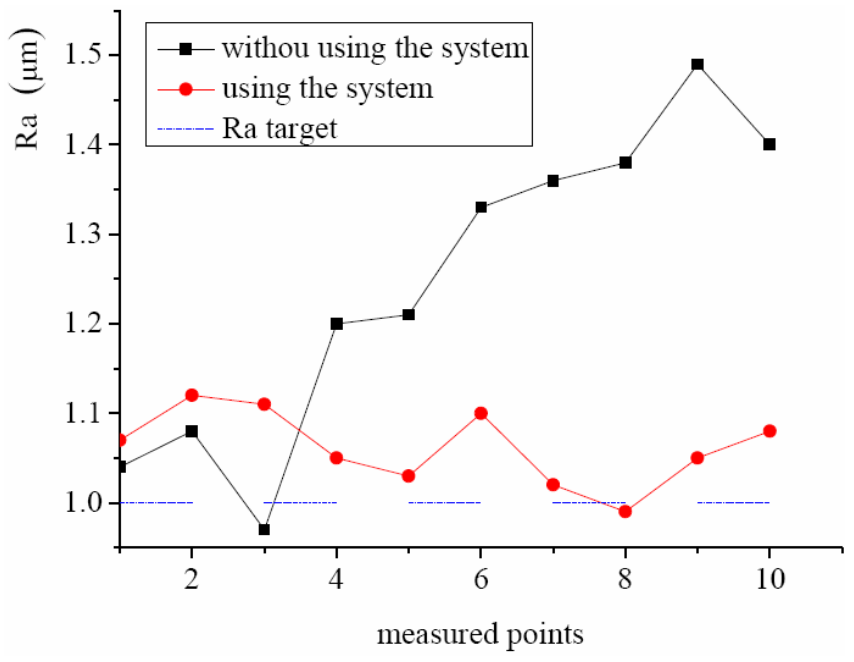

\section{Grinding experiment}

To verify the effectiveness of the on-line roughness monitor system, the grinding experiments were conducted. The grinding experiments were performed on a special NC grinding machining, and grinding area is a ring on inner surface, as shown in Figure 1 shaped parts. Pre-set grinding parameters were: $s_{t}=0.5 \mathrm{~mm} / \mathrm{r} ; a=100 \mu \mathrm{m} ; R a=1.0 \mu \mathrm{m}$; $d s=69.626 \mathrm{~mm} ; k=1$. The initial $v_{s}$ and $v_{w}$ optimised by ANN2 were $30.82 \mathrm{~m} / \mathrm{s}$ and $26.71 \mathrm{~mm} / \mathrm{s}$ respectively, then $n_{s}=8,542 \mathrm{rpm}$ and $n_{w}=4 \mathrm{rpm}$. Using the above parameters, two experiments were done, in first time the on-line roughness monitor system was not enabled in first time and was enabled in second time. After each grinding, 
the ten-point which were selected in grinding area were measured roughness using TESA RUGOSURF portable roughmeter. The grinding results were shown in Figure 8 and the $n_{s}$ and $n_{w}$ in second experiment were shown in Figure 9.

As shown in Figure 8, the roughness instability increased in first grinding, and the roughness of the second experiments were relatively stable. The on-line roughness monitor system was proved to be effective by grinding experiment.

Figure 9 The changed of $n_{s}$ and $n_{w}$ after using grinding online monitoring system (see online version for colours)

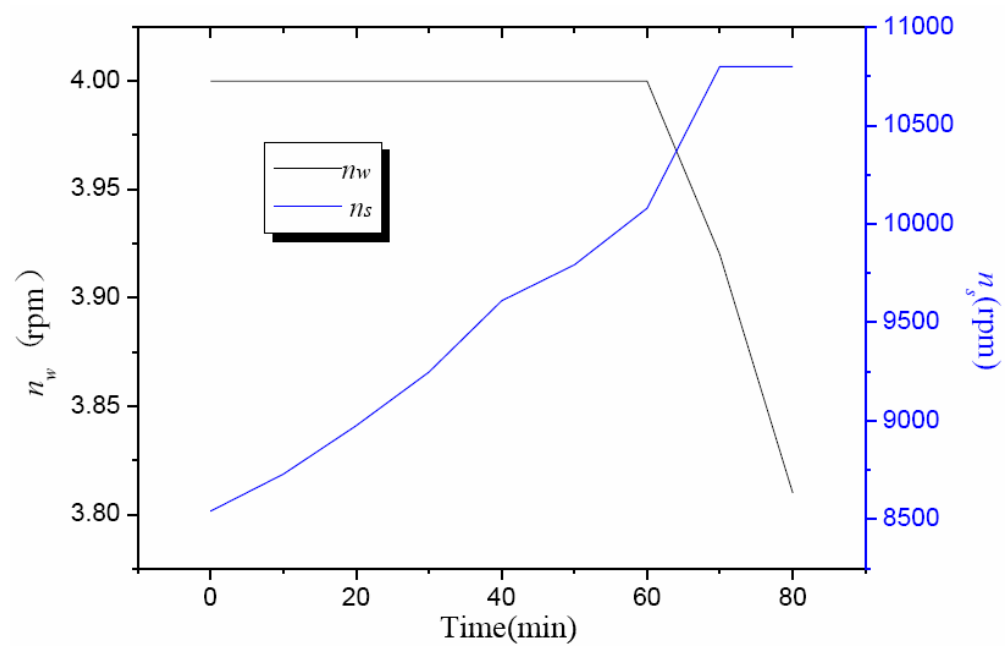

\section{Conclusions}

In order to achieve high surface quality in ceramic grinding, the on-line roughness monitor system was proposed in this paper, and the conclusions below had been obtained:

1 using the online roughness monitor system, the surface quality of ceramic grinding could be significantly improved and the roughness were relatively stable in whole process of grinding

2 the 'decoupling' law was present to eliminate the impact of other grinding on the $\mathrm{AE}$ signals, then the AE signals could real reflect wheel states

3 in ceramic grinding, the surface roughness of workpiece was difficultly controlled. The proposed method can be used for hard brittle materials processing, make processing process under control

4 based this work, the further research should be improved in two aspects: one way is to build smart grinding database, and another way is to use multiple sensors fusion to monitoring grinding condition. 


\section{Acknowledgements}

This project supported by the Fundamental Research Funds for the Central Universities of China [grant no. DUT10RC (3)108].

\section{References}

Banerjee, J.K. and Hillier, M.J. (1972) 'Some observations on the effects of wheel wearland on workpiece surface finish during flat surface grinding with cross-feed', First World Conference on Industrial Tribology, New Delhi, p.5.

Blum, T. and Dornfeld, D.A. (1993) 'Grinding process feedback using acoustic emission', 4th International Grinding Conference and Exposition, Society of Manufacturing Engineering, Dearborn, Michigan, Vol. 42.

Byrne, G., Dornfeld, D.A., Inasaki, I., Ketteler, G., Konig, W. and Teti, R. (1995) 'Tool condition monitoring (TCM) - the status of research and industrial application', Annals of the CIRP, Vol. 44, No. 1, pp.547-561.

Dornfeld, D.A. and Cai, H.G. (1984) 'An investigation of grinding and wheel loading using acoustic emission', Journal of Engineering for Industry, Vol. 106, No. 1, pp.28-33.

Inasaki, I. and Okamura, K. (1989) 'Monitoring of dressing and grinding process with acoustic emission', Annals of the CIRP, Vol. 34, No. 1, pp.277-280.

Kedrov, S.M. (1980) 'Investigation of surface finished in cylindrical grinding operations', Machines and Tooling, Vol. 51, No. 3, p.40.

Konig, W. and Kumplen, T. (1993) 'Dressing and sharpening process', Process Monitoring in Grinding, Production Engineering Vol. 1, No. 1, pp.27-30.

Konig, W. and Meyen, H.P. (1990) 'AE in grinding and dressing: accuracy and process reliability', SME Technical Paper, MR 90-526, $20 \mathrm{p}$.

Kwak, J-S. and Song, J-B. (2001) 'Trouble diagnosis of the grinding process by using acoustic emission signals', International Journal of Machine Tools \& Manufacture, Vol. 41, No. 6, pp.899-913

Malkin, S. (1989) Grinding Technology: Theory and Applications of Machining with Abrasives, Halsted Press, New York.

Meyen, H.P. (1991) Acoustic Emission (AE) - Mikroseismik im SchleifprozelJ, RWTH Aachen.

Snoeys, R., Peters, J. and Decneut, A. (1974) 'The significance of chip thickness in grinding', Annals of the CIRP, Vol. 23, No. 2, p.227

Wakuda, M. and Inasaki, I. (1991) 'Detection of malfunctions in grinding', 1st Int. Conf. on Acoustic Emission in Manufacturing, pp.494-501.

Wang, K., Sheng, X. and Kang, R. (2010) 'Volumetric error modeling, measurement and compensation for measurement - processing integrated machine tool', Proceedings of the Institution of Mechanical Engineers, Part C, Journal of Mechanical Engineering Science, Vol. 224, No. 11, pp.2477-2486. 